Disclosure of Interest: J. Smolen Grant/research support from: Abbvie, Janssen, Eli Lilly and Company, MSD, Pfizer, Roche, Consultant for: Abbvie, Amgen, AstraZeneca, Astro, BMS, Celgene, Celltrion, Chugai, Gilead, Glaxo, ILTOO, Janssen, Eli Lilly and Company, Medimmune, MSD, Novartis-Sandoz, Pfizer, Roche, Samsung, Sanofi, UCB, Speakers bureau: Abbvie, Amgen, Astra-Zeneca, Astro, BMS, Celgene, Celltrion, Chugai, Gilead, Glaxo, ILTOO, Janssen, Eli Lilly and Company, Medimmune, MSD, Novartis-Sandoz, Pfizer, Roche, Samsung, Sanofi, UCB, Z. Li: None declared, R. Klar Employee of: Quintiles IMS Holdings, Inc., L. Xie Employee of: Eli Lilly and Company, D. Walker Employee of: Eli Lilly and Company, A. Ghizdavescu Employee of: Eli Lilly and Company, R. Ortmann Employee of: Eli Lilly and Company, M. Dougados Grant/research support from: Abbvie, Pfizer, Eli Lilly and Company, Novartis, UCB, Merck, Roche, BMS, Consultant for: Abbvie, Pfizer, Eli Lilly and Company, Novartis, UCB, Merck, Roche, BMS

DOI: 10.1136/annrheumdis-2017-eular.1311

\section{FRI0097 REPAIR OF JOINT DAMAGE IN NEWLY DIAGNOSED RHEUMATOID ARTHRITIS PATIENTS OCCURS BUT DOES NOT RELATE TO PREVIOUS SUPPRESSION OF INFLAMMATION; AN 8-YEARS SUB ANALYSIS IN THE BEST-COHORT}

J.A. van der Pol ${ }^{1}$, G. Akdemir ${ }^{1}$, M. van den Broek ${ }^{1}$, L. Dirven ${ }^{1}$, P. Kerstens ${ }^{2}$, W.F. Lems ${ }^{3}$, I.M. Markusse ${ }^{1}$, T.W. Huizinga ${ }^{1}$, C.F. Allaart ${ }^{1} .{ }^{1}$ Department of Rheumatology, Leiden University Medical Center, Leiden; ${ }^{2}$ Department of Rheumatology, Westfries Gasthuis, Hoorn; ${ }^{3}$ Department of Rheumatology, VU Medical Center, Amsterdam, Netherlands

Background: Joint damage in rheumatoid arthritis (RA) is thought to be irreparable. We hypothesized that in patients where inflammation is well suppressed for a long time, repair may be possible.

Objectives: To investigate whether reversal of erosions and joint space narrowing (JSN) in RA occurs and whether clinical variables predict repair

Methods: In the BeSt study, patients with active early RA (ACR 1987 criteria, arthritis symptoms $<2$ years) were randomized to 4 treatment strategies, each with the aim to ensure and maintain suppression of disease activity by adjusting medication based on three-monthly calculations of the 44-joint Disease Activity Score (DAS), target $\leq 2.4$. Radiographic joint damage was assessed yearly, using the Sharp/van der Heijde score (SHS). In this analysis, 8-years data of the study were used. Repair of erosions or JSN was defined at the individual joint level as a reduction of $\geq 1$ SHS point compared to the previous available X-ray, present in $>2$ consecutive visits and with $>3$ out of 4 independent scorers agreeing. Radiographs were scored in random order per patient, blind for patient identity and treatment arm. Multiple logistic regressions were applied at the patient level for associations between achieving repair and maximum duration of previous remission, mean DAS until repair, previous prednisone use, previous infliximab use, anti-citrullinated protein antibody (ACPA), gender, age and randomization arm. All models were adjusted for mean joint damage over time in the group with repair. In the group without repair, the models were corrected for mean damage over time until mean time point of repair in the group with repair.

Results: Seven out of 508 patients did not have any X-ray images taken in the study. Of the remaining 501 patients, 320 had damage in at least 1 joint and thus could potentially show repair. In total, 2395 X-rays were available, on average 7.5 per patient (range 2-9). Median SHS after 8 years in these patients was 10 (IQR 4-21, range 0-234), and mean (SD) DAS from month 3 was 2.00 (0.67). Repair was seen in 17 patients, 3.3\%; 10 had reduction of JSN, 6 of erosions, 1 had repair of both JSN and erosions. In 14 patients repair was seen in 1 joint, in 3 patients repair was seen in 2 joints (same time point). Mean (SD) time to repair was $44.1(20.1)$ months. Ten of 17 patients $(59 \%)$ had previously achieved DAS-remission, compared to $100 \%$ of the patients who at a matching time point showed no repair. Adjusted for mean SHS until repair, we found no associations with repair for duration of remission, mean DAS until repair, gender, age, presence of ACPA, or previous exposure to prednisone or infliximab (table 1). Apart from a trend towards fewer patients with repair in the initial infliximab study arm, there were no differences in any of the groups in any of the regression analyses.

Table 1. Results of multiple logistic regression models to investigate associations with repair $(n=17)$

\begin{tabular}{|c|c|c|c|}
\hline & OR & $95 \% \mathrm{Cl}$ & $\mathbf{P}$ \\
\hline Duration of previous remission* & - & - & - \\
\hline Mean DAS from month 3 to time of repair & 1.39 & $0.77-2.51$ & 0.270 \\
\hline Previous prednisone & 1.09 & $0.385-3.09$ & 0.871 \\
\hline Previous infliximab & 0.599 & $0.206-1.74$ & 0.347 \\
\hline ACPA & 1.51 & $0.413-5.53$ & 0.533 \\
\hline Gender & 1.13 & $0.401-3.16$ & 0.822 \\
\hline Baseline age & 1.01 & $0.975-1.05$ & 0.548 \\
\hline \multicolumn{4}{|l|}{ Randomization arm } \\
\hline Sequential monotherapy & ref & - & - \\
\hline Step-up combination therapy & 0.797 & $0.231-2.75$ & 0.721 \\
\hline Initial combination with prednisone & 0.597 & $0.158-2.26$ & 0.448 \\
\hline Initial combination with infliximab & 0.147 & $0.0173-1.25$ & 0.080 \\
\hline
\end{tabular}

All models were adjusted for mean Sharp/van der Heijde score until repair DAS: disease activity score, ACPA: anti-citrullinated peptide antibody

*No results due to $100 \%$ remission in non-repair comparator group

Conclusions: In this early RA cohort, during 8 years treated to target DAS $\leq 2.4$, repair of JSN and erosions was seen in 17 patients (3.3\%), which supports that repair occurs in early RA. However, repair is a rare phenomenon, and does not seem to relate to previous inflammation or other predictors in this cohort.

Disclosure of Interest: J. van der Pol: None declared, G. Akdemir: None declared, M. van den Broek: None declared, L. Dirven: None declared, P. Kerstens: None declared, W. Lems Speakers bureau: Speakersfee/advosory boards Pfizer, MSD, Eli Lilly, Abbvie, I. Markusse: None declared, T. Huizinga: None declared, C. Allaart Grant/research support from: The BeSt study was supported by a government grant from the Dutch Insurance Companies, with additional funding from Schering-Plough B.V. and Janssen B.V. DOI: 10.1136/annrheumdis-2017-eular.2270

\title{
FRI0098 ELEVATED MULTI-BIOMARKER DISEASE ACTIVITY (MBDA) PREDICTS RELAPSES IN RA PATIENTS IN SUSTAINED REMISSION TAPERING TUMOUR NECROSIS FACTOR INHIBITOR THERAPY- RESULTS FROM THE RANDOMIZED CONTROLLED RETRO STUDY
}

J. Rech $^{1,1}$, M. Hagen ${ }^{1}$, M. Englbrecht ${ }^{1}$, J. Haschka ${ }^{2}$, M. Reiser ${ }^{1}$, A. Kleyer ${ }^{1}$, A. Hueber $^{1}$, B. Manger ${ }^{1}$, C. Figuereido ${ }^{3}$, J. Fogagnolo Cobra ${ }^{3}$, H.-P. Tony ${ }^{4}$, S. Finzel ${ }^{5}$, S. Kleinert ${ }^{6}$, J. Wendler ${ }^{6}$, F. Schuch ${ }^{6}$, M. Ronneberger ${ }^{6}$

M. Feuchtenberger ${ }^{7}$, M. Fleck ${ }^{8}$, K. Manger $^{9}$, W. Ochs ${ }^{10}$, M. Schmitt-Haendle ${ }^{10}$ H.-M. Lorenz ${ }^{11}$, H. Nuesslein ${ }^{12}$, R. Alten ${ }^{13}$, J. Henes ${ }^{14}$, K. Krueger ${ }^{15}$, G. Schett ${ }^{1}$. ${ }^{1}$ University of Erlangen-Nuremberg, Erlangen, Germany; ${ }^{2}$ St. Vincent Hospital, Vinforce Study Group, Medical University of Vienna, Vienna, Austria; ${ }^{3}$ Institutio de Rheumatologia, Sao Paolo, Brazil; ${ }^{4}$ University of Wuerzburg, Internal Medicine 2, Wuerzburg; ${ }^{5}$ University Medical Center Freiburg, Rheumatology and Clinical Immunology, Freiburg; ${ }^{6}$ Rheumatology Clinical Practice Erlangen, Erlangen: ${ }^{7}$ Rheumatology Practice and Department of Internal medicine 2, Clinic Burghausen, Burghausen; ${ }^{8}$ Asklepios Medical Center, Department of Rheumatology and clinical Immunology, Bad Abbach;

${ }^{9}$ Rheumatology Practice Bamberg, Bamberg; ${ }^{10}$ Rheumatology Practice Bayreuth, Bayreuth; ${ }^{11}$ University of Heidelberg, Medicine 5, Heidelberg;

${ }^{12}$ Rheumatology Practice Nuremberg, Nuremberg; ${ }^{13}$ Schlosspark Klinik, Internal Medicine/Rheumatology, Berlin; ${ }^{14}$ University of Tuebingen, Centre for Interdisciplinary Clinical Immunolog, Tuebingen; ${ }^{15}$ Praxiszentrum St.Bonifatius, Munich, Germany

Background: Tumor necrosis factor inhibitors (TNFi) are the most frequently used bDMARDs in RA patients. TNFi induces remission in a substantial numbers of patients. Once remission, particularly sustained remission is achieved the question arises whether TNFi can be successfully tapered. To date biomarkers, which can help to predict if TNFi can be tapered or stopped, remain to be developed.

Objectives: To test whether residual subclinical inflammation assessed by multibiomarker disease activity (MBDA) predicts the risk of disease relapse after tapering or stopping TNFi treatment in RA patients in sustained remission.

Methods: Sub-analysis of TNFi treated patients of the RETRO study, a randomized-controlled study in RA patients in sustained (>6 month) DAS28 remission comparing 3 different DMARD treatment strategies (continuation of full dose, $50 \%$ dose tapering, stopping after $50 \%$ dose tapering). Patients were followed over one year for the occurrence of relapses as defined by leaving DAS28-ESR remission (>2.6 units) (1). Vectra-DA tests were done in the baseline samples of all patients included into the RETRO study. MBDA score was calculated according to previously defined algorithms with low MDBA score defined as $<30$ units and moderate to high scores as $\geq 30$ units (2).

Results: Of the 151 patients included in the RETRO study, 42 received TNFi treatment (mean age: 56 ys, 25 (60\%) females, 78\% concomitant csDMARDs; $69 \%$ ACPA/RF positive. Baseline demographic and disease specific characteristics of these patients were comparable to the non-TNFi treated patients of the RETRO study. 26/42 patients (62\%) had low MBDA scores at baseline, while 16/42 (38\%) had moderate/high scores. Relapse rates were significantly (chi square $p=0.016$ ) lower in RA patients with low MBDA scores ( $\mathrm{N}=8$ of $26 ; 31 \%)$ than in those with moderate/high scores ( $\mathrm{N}=11$ of $16 ; 69 \%)$ (Figure; left graph). When separately analyzing only patients tapering $\mathrm{TNFi}(\mathrm{N}=29)$, relapse rates were moderate in

All TNFi treated patients

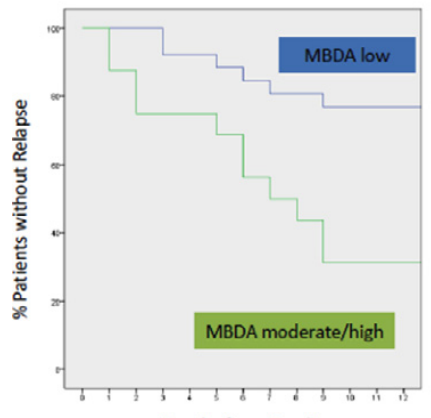

Months from Baseline
Patients tapering/stopping TNF

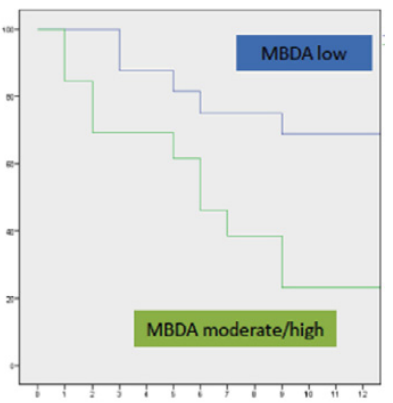

Months from Baseline 